\title{
Prevalência de Transtornos Mentais e Percepção de Suporte Familiar em Policiais Civis
}

\author{
Prevalence of Mental Disorders and Perception \\ of Family Support in the Civil Police
}

Prevalencia de Trastornos Mentales y Percepción de Soporte Familiar en Policías Civiles.

\section{Maria Cristina d'Avila de Castro \\ \& Roberto Moraes Cruz}

Universidade Federal

de Santa Catarina

http://dx.doi.org/10.1590/1982-370300702013 
Resumo: Este estudo transversal, exploratório-descritivo, verificou a prevalência de Transtorno Mental e Comportamental (TMC) e percepção do suporte familiar em Policiais Civis de Santa Catarina, afastados do trabalho pela Perícia Médica do Estado, no período entre 2009 e 2010. Utilizaram-se na coleta de dados: a) planilha de dados de prevalência de TMC da Secretaria de Estado da Administração/SC; b) inventário de percepção de suporte familiar; c) investigação das dimensões desse suporte e do processo de adoecimento relacionado ao trabalho, na perspectiva do policial e do familiar. Os dados de prevalência referem-se aos afastamentos por TMC ( $n=148)$ no período mencionado e os de suporte familiar, aos policiais $(n=19)$ e familiares $(n=13)$ participantes da entrevista. Detectou-se que, para cada 100 policiais, 4,6 foram afastados por TMC. A percepção do suporte familiar por parte dos policiais indicou ser ele um recurso importante durante o período de afastamento do trabalho, na recuperação e no retorno à atividade, corroborando a existência de uma associação inversa entre nível de apoio social e sofrimento psíquico. Conclui-se que o incentivo à valorização do suporte familiar e o estímulo às relações interpessoais na família, no trabalho e nas relações sociais ampliadas, tornam-se ferramentas importantes para a percepção de bem-estar e se relacionam com o aumento da satisfação de vida, da autoestima e, por consequência, contribuem para o controle dos sintomas.

Palavras-chaves: Policial. Transtornos mentais. Apoio social.

Abstract: This cross-sectional, exploratory, and descriptive study examined the prevalence of mental and behavioral disorder (MBD) and perception of family support in the civil police of Santa Catarina, signed off work by State medical experts during 2009-2010. The following were used in data collection: a) a datasheet of MBD prevalence from the State Department of Administration/SC; b) an inventory of perceived family support; c) inquiry about the dimensions of this support and the process of work-related illness from the perspective of police officers and their families. The prevalence data provide absence because of $\operatorname{MBD}(n=148)$ in the specified period and the family support provided to police officers $(n=19)$ and their families $(n=13)$ who participated in the interview. We found that, in every 100 police officers, 4.6 were absent because of MBD. The police officers' perception of family support indicated this to be an important resource during the period of absence from work, in recovery, and in returning to full activity, revealing an inverse association between the level of social support and psychological distress. It was concluded that the incentive value of family support and the encouragement of interpersonal relationships in the family, at work, and in extended social relations are important tools for the perception of well-being and are associated with an improved life satisfaction and self-esteem, contributing to symptom control.

Keywords: Police officer. Mental disorders. Social support.

Resumen: Este estudio transversal, exploratorio-descriptivo, verificó la prevalencia deTrastorno Mental y del Comportamiento (TMC) y la percepción de soporte familiar en Policías Civiles de Santa Catarina, incapacitados por la Pericia Médica del Estado entre 2009 y 2010. Para la toma de datos fueron utilizados a) Banco de datos de prevalencia de TMC de la Secretaría de Estado de la Administración/SC; b) inventario de percepción de soporte familiar; c) investigación de las dimensiones de ese soporte y del proceso de enfermedad relacionado al trabajo, en la perspectiva del policía y del familiar. Los datos de prevalencia se refieren a las incapacidades por TMC $(n=148)$ en el periodo mencionado y, los de soporte familiar a los policías $(n=19)$ y familiares $(n=13)$ que participaron en la entrevista. Se encontró que 4,6 de cada 100 policías fueron incapacitados por TMC. La percepción del soporte familiar por parte de los policías indicó que éste es un recurso importante durante el periodo de incapacidad laboral, en la recuperación y en el retorno al trabajo, corroborando la existencia de una asociación inversa entre el nivel de apoyo social y el sufrimiento psíquico. Se concluye que el incentivo a la valorización del soporte familiar y el estímulo a las relaciones interpersonales en la familia, en el trabajo y en las relaciones sociales ampliadas, se convierten en herramientas importantes para la percepción de bienestar y se relacionan con una mayor satisfacción de la vida, de la autoestima y, por consecuencia, contribuyen para el control de los síntomas.

Palabras clave: Policía. Transtornos mentales. Apoyo social. 
1 Prevalência: número de pessoas que, em uma população definida, tem uma doença ou condição específica em um determinado ponto do tempo (Medronho, Bloch, Luiz, \& Werneck, 2009).

\section{Introdução}

O vínculo entre trabalho e condições psicológicas dos trabalhadores tem adquirido visibilidade nas pesquisas acadêmicas no início do século XXI, embora ainda com algumas dificuldades para definir o nexo que os aproxima (Glina, Rocha, Batista \& Mendonça, 2001; Jaques, 2007). No Brasil, há contribuições específicas sobre a prevalência de transtornos mentais em diferentes ocupações (Fortes, Villano \& Lopes, 2008; lacoponi, 1997), e, em Santa Catarina, estudo realizado por Campos e Cruz (2007) demonstrou a prevalência ${ }^{1}$ de Transtornos Mentais e Comportamentais (TMC) em servidores públicos das Secretarias de Educação, Segurança Pública e Administração.

Diferentes quadros de TMC têm sido qualificados como motivadores de Licenças para Tratamento de Saúde (LTS) e de benefícios de saúde e previdenciários, fato que indica a necessidade de maior atenção às condições laborais na medida em que os agravos à saúde relacionados à ocupação funcional incapacitam parcial ou totalmente os trabalhadores, restringindo sua autonomia e sua capacidade produtiva (Cruz, 2010).

A profissão do policial reveste-se de características específicas que podem contribuir para o adoecimento, entre elas, a demanda de dedicação integral ao trabalho, o que leva a atividade profissional a ocupar espaços de sua vida pessoal. Como consequência, desenvolvem-se comportamentos de desconfiança no policial, do que resulta maior atenção a atitudes suspeitas nos ambientes em que está presente e maior desconfiança nas relações sociais (Minayo, Souza \& Constantino, 2007; Souza \& Minayo, 2005). A isso, acrescentamse os problemas decorrentes do contato do policial com a violência e a criminalidade. $\mathrm{O}$ uso permanente de arma de fogo, o risco real de ser ferido ou morto, inclusive em espaços sociais, e o de sua família ser atingida como represália a algum procedimento realizado no exercício de sua função também são fontes de tensão a lhe agredir a saúde (Andrade, Souza \& Minayo, 2009).
Considerem-se as rotinas ocupacionais estressoras que se somam às condições e à organização do trabalho (Spode \& Merlo, 2006). A sobrecarga de trabalho associada à extensão dos plantões alerta para a urgência de medidas de gerenciamento dos problemas decorrentes do cotidiano vivido pelos policiais, sob pena da manutenção de um estado permanente de desequilíbrio social (Andrade et al., 2009; Anchieta \& Galinkin, 2005; Minayo \& Souza, 2003).

Diante desse cenário, importante é considerar que estudos conferem ao suporte social de pessoas significativas, advindas de sua rede de relações, um papel de realce frente às situações de tensão. Esse fator mostra-se capaz de reduzir os riscos do impacto de eventos estressores e influenciar na percepção de ameaça à saúde, bem como no desenvolvimento do curso de um transtorno como resposta aos eventos estressores (Savoia, 1999; Seidl, Trócoli \& Zanon, 2001). É uma dimensão de experiência individual de manutenção de bem-estar e de proteção frente a tensões cotidianas e de demonstração de habilidades de gerenciamento da saúde, incluídos os hábitos de cuidado e a capacidade de adaptação em uma crise (Sluzki, 1997). São as redes de relações - das quais se destacam os suportes sociais e familiares - a que se recorre primordialmente em busca de amparo e proteção e são elas que testemunham as situações de crise propriamente ditas (Zuma, 2004). O importante é ter com quem contar e para quem contar (Ornelas, 2008).

O constructo suporte social é apontado por Cunha et al. (2009) como tendo adquirido grande importância na atualidade na área da Psicologia da Saúde, por apresentar direta relação entre sua existência e a prevenção e recuperação de doenças físicas, mentais e afetivas. O suporte social está entre os fatores de redução do impacto causado por eventos estressores, daí sua relevância no aprofundamento de pesquisas nesta área (Antunes \& Fontaine, 2005). Entretanto, observa-se uma grande variedade de termos que se referem ao suporte social e rede social como: rede social de apoio, rede de apoio social, rede de suporte social, rede de apoio 
social e afetivo, rede de relações, suporte familiar, suporte psicossocial, suporte social de apoio, apoio familiar e apoio psicológico (Gonçalves, Pawlowski, Bandeira \& Piccinini, 2011).

Não é clara a distinção entre rede social e suporte social. Rede social são todos os membros com os quais o indivíduo se relaciona, mas somente uma parte restrita dessas ligações é considerada laço ativo (Ornelas, 2008), ou seja, que proporcionam sociabilidade e suporte social. O suporte social aparece referendado como sendo um metaconstruto composto de elementos conceituais nos achados de Matsukura, Marturano e Oishi (2002). Sistemas de suporte social são constituídos de "padrões duradouros de vínculos que contribuem de maneira significativa para a manutenção da integridade física e psicológica do indivíduo" (Campos, 2004, p. 141). Está associado à informação que conduz o indivíduo a acreditar que é estimado, valorizado e parte integrante de uma rede de comunicação e obrigação mútuas e considera o suporte social um amortecedor de estresse, concluindo que este desempenha uma função de facilitador da confrontação e adaptação em situação de crise (Campos, 2004; Ornelas, 2008). Assim, para que o suporte social proporcione um sentimento de proteção e apoio à pessoa, é necessário estabelecer uma forma de relacionamento interpessoal que contribua para o bem-estar psicológico. A diferença entre rede social e suporte social está na qualidade das relações estabelecidas na rede social no sentido de apoio a situações de crise (suporte).

A família é um sistema de suporte sendo referência do cuidado básico do ser humano e, quando presente, estável, sensível, ativa e confiável, protege a pessoa contra doenças, atua como agente de ajuda e encaminhamento, afeta a pertinência e rapidez da utilização de serviços de saúde, acelera os processos de cura, aumenta a sobrevida (Campos, 2004). É apontado como aspecto principal não apenas para a sobrevivência dos indivíduos, mas também para a proteção e a socialização de seus componentes, transmissão do capital cultural, econômico e da propriedade do grupo, bem como das relações de gênero e de solidariedade em geral (Carvalho \& Almeida, 2003). Tanto o suporte familiar como o social advindo da rede social é dinâmico e se apresenta de forma diferente em cada momento de vida do indivíduo, família ou grupo com repercussão direta nas relações que o indivíduo estabelece com o mundo.

Assim, a percepção do policial quanto à qualidade do suporte social e familiar construído durante sua vida é fator essencial para sua saúde, inclusive para a percepção de segurança emocional e compromisso nas relações (Guest \& Biasini, 2001). O suporte social e familiar são indicadores de que a retaguarda dessas redes pode fazer o diferencial na manutenção da saúde do policial e conferir a ele resiliência e fortalecimento no enfrentamento das demandas nocivas do trabalho.

O objetivo deste estudo é examinar a prevalência de diagnósticos de TMC em policiais civis afastados do trabalho em Licença para Tratamento de Saúde (LTS) no período 20092010 e caracterizar as dimensões do suporte familiar no âmbito da investigação da relação saúde-trabalho do policial civil. A expectativa é contribuir na investigação dos processos de saúde no trabalho em policiais civis, com base em achados teórico-metodológicos relevantes e em estudo empírico sobre a prevalência de TMC e na percepção de suporte familiar por parte dos policiais e membros de sua família. Os resultados poderão auxiliar na construção de intervenções de promoção e proteção à saúde dos policiais civis, capazes - tais intervenções - de garantir melhor qualidade de vida para esses profissionais e refletir ainda nos cofres públicos, na medida em que a atenção à saúde do trabalhador reduz o número de afastamentos do trabalho.

\section{Materiais e métodos}

\section{Participantes e desenho do estudo}

Trata-se de uma pesquisa transversal de caráter exploratório e descritivo, aplicada em policiais civis de Santa Catarina afastados do trabalho pela Perícia Médica do Estado 
com diagnóstico de TMC, durante os anos de 2009 e 2010. Foram contempladas as abordagens quantitativa, cujos resultados se referem a todos os policiais licenciados do trabalho para tratamento de saúde (LTS) devido ao diagnóstico de TMC $(n=148)$, e qualitativa, referente aos policiais desta amostra que aceitaram tomar parte nas entrevistas $(n=19)$ e seus familiares $(n=13)$, totalizando 32 participações.

Os dados foram tratados estatisticamente e descrevem as características da população de afastados por TMC $(n=148)$, delineando um panorama baseado em dados quantitativos. Os resultados das entrevistas $(n=32)$, após serem dispostos em quadros sínteses para identificação de similaridades e diferenças sobre a percepção dos policiais e de seus familiares, sobre o suporte recebido, foram relacionados com os resultados do Inventário de Percepção do Suporte Familiar (IPSF) e com o banco de dados, mas somente os resultados significativos serão apresentados. São considerados significativos resultados de $p<0,05$ (Dancey \& Reidy, 2008).

\section{Instrumentos}

a) Planilha de dados do Sistema Integrado de Gestão de Recursos Humanos (SIGRH): sistema informatizado desde 1992. Nele estão registrados dados da vida pessoal e funcional de todos os servidores públicos do Estado de SC.

b) Inventário de Percepção de Suporte Familiar (IPSF): desenvolvido e validado no Brasil por Baptista $(2005,2009)$, apresenta 42 itens e três dimensões: 1) Afetivo-Consistente; 2) Adaptação Familiar; 3) Autonomia. As questões são fechadas e respondidas em uma escala de três pontos, modelo Likert de sentido e pontuação crescente: $0=$ "Quase Nunca ou Nunca", 1 = "Às vezes" e 2 = "Quase Sempre ou Sempre". Quanto maior a pontuação de todas as dimensões da escala, melhor é o suporte familiar na percepção do participante. Foi aplicado individualmente para avaliar o quanto os policiais percebiam o suporte familiar durante o afastamento do trabalho por problemas de saúde e como instrumento de validade externa, isto é, como um parâmetro de correspondência aos achados obtidos na população pesquisada em relação a outros resultados sobre o suporte familiar, coletados por meio da entrevista.

c) Roteiro de entrevista: estruturado para investigar as dimensões do suporte familiar na percepção do policial e do familiar durante o afastamento do policial do trabalho porTMC.

\section{Procedimentos de coleta de dados}

Após aprovação do Comitê de Ética e Pesquisa em Seres Humanos da Universidade Federal de Santa Catarina, a pesquisa foi apresentada ao Delegado Geral da Polícia Civil de Santa Catarina e à Perícia Médica do Estado (Gerência de Controle de Benefícios/GECOB), para facilitação da realização das etapas previstas no estudo.

O acesso ao banco de dados (SIGRH) sem a identificação dos policiais aconteceu logo que o projeto foi apresentado à Perícia Médica. Entretanto, o contato com os policiais afastados do trabalho por TMC para a realização da etapa qualitativa da pesquisa, por questões éticas, necessitou de uma série de procedimentos relatados a seguir.

Com o ofício circular n 99/2011/GECOB apresentou-se a pesquisa, a pesquisadora e os esclarecimentos éticos necessários e convidou-se o policial a participar da pesquisa. Concomitantemente, foi divulgada a pesquisa no site da Polícia Civil (PC) e na intranet da instituição policial alertando sobre o ofício enviado pela GECOB para policiais em LTS por TMC, com a indicação do nome e telefone da pesquisadora, para contato, caso desejassem saber mais sobre o estudo ou se, de antemão, estivessem interessados em participar.

Foram enviadas 148 correspondências (total de policiais afastados por TMC no período de 2009 a 2010) em julho de 2011. Retornaram para a GECOB 55 correspondências por problemas de endereço insuficiente, desconhecido ou por mudança de endereço. Destas, foram reenviadas 26 cartas, após atualização 
de endereço via telefone com o policial ou via Recursos Humanos da PC. Após envio das correspondências foram feitos contatos telefônicos com os 67 policiais que não haviam dado nenhum retorno para saber se haviam recebido o ofício e se tinham alguma dúvida a esclarecer, reiterando a importância da pesquisa e estimulando a participação. Ao final de todo o processo para a realização da etapa qualitativa da pesquisa, retornaram 11 correspondências com oTCLE assinado, e oito policiais fizeram contato diretamente com a pesquisadora (por e-mail ou por telefone), totalizando 19 policiais dispostos a participar das entrevistas.

Terminada essa etapa (executada nos meses de julho e agosto de 2011), foram marcadas as entrevistas com os policiais e familiares. A realização da entrevista com os familiares, a quem o acesso era dado pelo policial, apresentou algumas dificuldades, ou por parte do policial, que não se mostrou à vontade para a realização do procedimento, ou pelo familiar, que não se dispôs a participar. Por fim, apenas 13 familiares participaram da pesquisa.

As entrevistas foram realizadas inicialmente com o policial e, enquanto ele respondia ao IPSF, o familiar era entrevistado. Os procedimentos para a execução da entrevista foram: a) explicação do roteiro de entrevista e aplicação do IPSF; b) solicitação para que o ambiente fosse adequado à realização da entrevista, somente com as interrupções absolutamente necessárias; c) solicitação de autorização para o uso do gravador de voz como recurso para a fidedignidade das informações, salientada a confidencialidade do conteúdo, conforme indicado no TCLE; d) destaque para o fato de que, além das informações fornecidas via entrevista, seriam obtidas outras informações oriundas do Sistema Integrado de Gestão de Recursos Humanos (SIGRH); e) reafirmação do compromisso de sigilo dos dados obtidos a ser utilizados somente em publicações científicas e eventos científicos, sem qualquer possibilidade de identificação do nome da pessoa entrevistada.

Não foi constatado nenhum risco durante o procedimento e, após o encerramento da entrevista, o que se ouviu dos participantes é que fora uma boa experiência, que lhes possibilitara organizar algumas ideias e pensamentos sobre o processo de afastamento.

\section{Tratamento e Análise dos dados}

A prevalência deTMC de todos os policiais civis afastados por esses transtornos em 2009 e 2010 $(\mathrm{n}=148)$ foi analisada com base nos dados do SIRGH, assim como o perfil da amostra geral estudada sem identificação dos incluídos. Foi realizada também uma análise estatística inferencial que associou as variáveis: sexo, escolaridade, idade, tempo de serviço, cargo e local de trabalho (lotação) e diagnóstico de TMC, segundo a Classificação Internacional das Doenças - $10^{\mathrm{a}}$ revisão (CID F). Algumas das variáveis foram agrupadas em categorias por similaridade para aumentar o seu poder estatístico. Para a análise das correlações entre os resultados das referidas variáveis, utilizou-se a correlação de Pearson. O teste qui-quadrado foi utilizado para examinar a existência de diferença significativa na distribuição dos quadros diagnósticos dos policiais afastados do trabalho no período estudado.

Dados oriundos do Roteiro de entrevista utilizados para investigar a percepção sobre o processo de afastamento do trabalho e a percepção de suporte familiar por parte dos participantes e seus familiares foram organizados com base nas seguintes dimensões temáticas: conflito entre o ideal e o real da profissão, imagem social da profissão, mudança de comportamentos, apoio afetivo e material frente ao processo de afastamento do trabalho, percepção do processo de adoecimento, percepção do processo de tratamento. Cada dimensão pretendeu analisar aspectos relativos à percepção do policial sobre a sua profissão, o processo de adoecimento e suporte recebido durante o seu afastamento. Conteúdos similares das respostas a cada dimensão do ponto de vista semântico foram organizados em quadros sínteses buscando sistematizar dados oriundos de cada participante com o objetivo de identificar diferenças e semelhanças na percepção dos policiais e de seus familiares. A tabela 1 descreve 
as perguntas do roteiro de entrevista e sua relação com as dimensões de suporte familiar:

As categorias da análise das entrevistas com os policiais, utilizadas nesse procedimento foram definidas com base no entendimento de que as perguntas do roteiro de entrevista rastreavam a percepção do suporte familiar por parte dos participantes. Foram elas:

a) visão da família sobre a profissão policial - a imagem que a família tem da profissão policial reflete no suporte familiar. As respostas foram codificadas em positiva (código 1), negativa (código 2) e ambos (3) na medida em que um mesmo policial deu respostas positivas e negativas para essa pergunta. b) desejo de que o filho seguisse a carreira policial - respostas a essa categoria estão associadas à imagem social e familiar da profissão e, consequentemente, à percepção do suporte familiar. As respostas sim, receberam o código 1 e as respostas não, receberam o código 2. As respostas sim, mas (condicionais) foram codificadas como sim e, portanto, receberam o código 1 .

c) relações sociais - restritas às relações familiares ou ampliadas refletem o suporte familiar. As respostas foram codificadas com 1 para aquelas que se relacionavam somente com a família e 2 para as que se relacionavam de forma ampliada (família, amigos, comunidade).

Tabela 1. Roteiro de entrevista com o policial participante.

\begin{tabular}{|c|c|}
\hline Dimensões & Perguntas \\
\hline $\begin{array}{l}\text { Conflito entre a } \\
\text { expectativa e o real da } \\
\text { profissão }\end{array}$ & $\begin{array}{l}\text { O que é ser policial hoje? O que você pensava quando entrou } \\
\text { para a polícia? Qual foi a ocorrência no trabalho que mais } \\
\text { marcou a sua vida? }\end{array}$ \\
\hline $\begin{array}{l}\text { Imagem social da } \\
\text { profissão }\end{array}$ & $\begin{array}{l}\text { Como você percebe que é visto pela família? Como você } \\
\text { percebe que é visto pelos amigos/comunidade? Você gostaria } \\
\text { que seu filho fosse policial? }\end{array}$ \\
\hline $\begin{array}{l}\text { Mudança de } \\
\text { comportamento }\end{array}$ & $\begin{array}{l}\text { Que mudanças ocorreram na sua vida desde que se } \\
\text { tornou policial? Você mudou o seu jeito de agir (atitudes, } \\
\text { comportamentos) quando se tronou policial? }\end{array}$ \\
\hline Apoio afetivo e material & $\begin{array}{l}\text { Você participa de algum grupo? O que você faz pra se divertir? } \\
\text { Com quem você compartilha ou divide quase tudo da sua vida? } \\
\text { Quem é a pessoa mais importante pra você? Quando você está } \\
\text { com problemas, que tipo de apoio você recebe: da família? } \\
\text { quais? dos amigos? quais? De que forma você pede ajuda? } \\
\text { Como as pessoas sabem que você está precisando de ajuda? } \\
\text { De que forma você ajuda sua família? O que você faz? Você } \\
\text { percebe que sua família deseja ajudá-lo? Como e o que eles } \\
\text { fazem? De que forma você demonstra afeto? }\end{array}$ \\
\hline $\begin{array}{l}\text { Apoio afetivo e material } \\
\text { frente ao processo de } \\
\text { afastamento do trabalho }\end{array}$ & $\begin{array}{l}\text { Com quem você conversou sobre isso (a percepção de que } \\
\text { não estava bem)? Com quem você contou para te ajudar? Levar } \\
\text { ao médico, cuidar? E hoje? O que você pensa que te levou a } \\
\text { precisar se afastar? }\end{array}$ \\
\hline $\begin{array}{l}\text { Percepção do processo } \\
\text { de adoecimento }\end{array}$ & $\begin{array}{l}\text { Quando você começou a perceber que não estava bem? } \\
\text { Pensando no que te levou ao afastamento por LTS, o que você } \\
\text { faria diferente se pudesse voltar no tempo? }\end{array}$ \\
\hline $\begin{array}{l}\text { Percepção do processo } \\
\text { de tratamento }\end{array}$ & $\begin{array}{l}\text { O que o médico disse que você teve/tem? Você concorda? Qual } \\
\text { o tratamento que o médico disse que você teria que fazer? Você } \\
\text { concorda? Que tipo de tratamento você fez/faz? }\end{array}$ \\
\hline
\end{tabular}


d) com quem compartilha quase tudo na vida-está diretamente relacionada ao suporte percebido. As respostas foram codificadas em 1 quando citavam membros da família e 2 quando se referiam a pessoas fora da família.

e) apoio recebido durante a vida - percepção de suporte familiar está igualmente relacionada à percepção de apoio da rede social mais próxima ou ampliada. As respostas foram codificadas em 1 para o apoio familiar, 2 apoio de membros da família e fora da família, 3 para pessoas de fora da família e 4 para ninguém.

f) apoio recebido durante a LTS - o afastamento do trabalho mobiliza necessidade de suporte familiar. As respostas foram codificadas 1 para família, 2 para ambos, 3 para pessoas de fora da família e 4 para ninguém.

g) para quem falou sobre seus sintomas - falar sobre o problema de saúde reflete necessidade de suporte. As respostas foram codificadas da mesma forma que a anterior.

h) com quem contou durante a LTS - o apoio recebido durante o afastamento do trabalho reflete suporte familiar. As respostas foram codificadas da mesma forma que a anterior.

O Roteiro de Entrevista foi composto de perguntas abertas, executado verbalmente, dentro de uma ordem prevista. Ao entrevistador cabia acrescentar ou suprimir itens, à medida que se fazia necessário obter maiores esclarecimentos, favorecendo a exploração aprofundada dos assuntos pertinentes aos objetivos do estudo. As categorias temáticas de análise foram formadas com base no modelo misto proposto por Laville \& Dionne (1999), no qual as categorias de análise são selecionadas antecipadamente. Essas categorias foram construídas a partir do roteiro de entrevista que está apoiado no aporte teórico da pesquisa.

Os resultados do IPSF foram tabulados conforme o padrão de escores totais do instrumento normatizado e determinado no procedimento. Este instrumento foi utilizado como critério de validade externa para o
Roteiro de Entrevista. A relação entre os resultados obtidos pela análise descritiva dos dados sobre idade, sexo, tempo de serviço, local de trabalho, TMC, resultado do IPSF e categorias de análise das entrevistas com os policiais, foi realizada com o SPSS.

\section{Resultados e Discussão}

A amostra estudada representa em torno de $4,6 \%$ da população geral de policiais civis em Santa Catarina. Os estudos brasileiros sobre TMC em policiais não apresentam dados de prevalência para que se possa ter um parâmetro, mas esse resultado indica que a cada 100 policiais, 4,6 são afastados do trabalho por TMC em algum momento da sua vida funcional. Estudos em populações de trabalhadores brasileiros realizados por Maragno, Goldbaum, Gianini, Novaes e César (2006) indicam um número de $42,6 \%$ de afastamentos por TMC, e, no estudo de Ludermir e Melo Filho (2002), o resultado é de $35 \%$.

Uma possível explicação para esse número reduzido de afastamentos por TMC em policiais civis de Santa Catarina em relação aos trabalhadores em geral pode estar relacionado com as perdas financeiras que o policial tem de arcar quando se afasta do trabalho. O policial afastado perde alguns benefícios monetários no salário (hora-extra, adicional noturno, por exemplo) e, como mostra o estudo de Baierle e Merlo (2008), há policiais que preferem trabalhar doentes a tirar licença de saúde (presenteísmo). Quando estes policiais procuram assistência médica ou psicoterápica, é comum receberem prescrição de afastamento do trabalho como uma medida importante para reconstituição de sua saúde, conforme citado pelos policiais durante as entrevistas: "Um ano e meio antes da crise de depressão eu estava muito estressada. Muito irritada, com mal-estar, não queria trabalhar, mas tinha que vir e me fechava na minha sala" (PC11). Além disso, os afastamentos por TMC sofrem discriminações conforme aponta o estudo de Baierle e Merlo (2008) e de Cantelli, Mota e Castro (2010) e como foi revelado na entrevista: "A reincidência da doença criou problemas na relação com meus 
colegas que começaram a me desqualificar, achando que era malandragem. Enquanto as pessoas não vivem isso, não compreendem e julgam. Isso é muito desgastante" (PC 16).

O perfil sociodemográfico dos policiais afastados por TMC em 2009 e $2010(n=148)$ compreende: idade média é de 45,5 anos ( $D p=9,31)$, moda é de 53 anos, amplitude amostral de 23 a 63 anos e maior concentração de policiais com idade entre 49 e 50 anos. No grupo dos policiais entrevistados $(n=19)$, o maior agrupamento permanece entre $40 \mathrm{e}$ 45 anos. No estudo de Maragno et al. (2006) sobre a população atendida pelo Programa de Saúde da Família em uma cidade de São Paulo, a faixa de idade de maior prevalência de TMC foi de 45 e 54 anos e, no estudo de Ferreira, Augusto e Silva (2008) sobre a saúde geral do policial, a maior prevalência de percepção de saúde negativa deu-se em policiais com mais de 39 anos de idade.

Dentro desse universo, o número de homens e mulheres ficou relativamente equilibrado $(51,3 \%$ de policiais do sexo feminino e $48,6 \%$ do sexo masculino). As pesquisas de Carvalho, Carvalho, Lucena, Coelho e Araújo (2008), Costa, Accioly Júnior e Maia (2007), Dantas, Brito, Rodrigues e Maciente (2010), Moraes, Pereira e Souza, (2001a), Oliveira e Bardagi (2010), Rosseti et al. (2008) e Silva, Fabbro e Heloani (2009) corroboram esse resultado, destacando que o número de mulheres com sintomas de sofrimento psíquico é maior que o de homens.

O nível de escolaridade predominante é o médio (43,9\%), seguido de 39,2\% do nível superior. Importante esclarecer que somente no concurso de 2010 foi exigido nível superior para todos os cargos. Em 2008, para os cargos de escrevente e investigador era exigido apenas nível médio. Como a amostra é somente dos policiais afastados, não se pode afirmar que esses resultados indicam o perfil escolar da população de policiais, mas pode-se pensar que os policiais afastados apresentam um bom nível de escolaridade, inclusive com $11,1 \%$ de policiais com especialização - como incentivo, o policial que faz especialização ganha um percentual a mais no seu salário base, o mesmo ocorrendo para aqueles com mestrado e doutorado. No estudo de Minayo e Souza (2003), referente à população geral da Polícia Civil do Rio de Janeiro, 53,2\% ( $n=1458)$ possuíam nível superior completo e 6,9\% pós-graduação, o que reflete uma tendência de aumento de escolaridade na categoria.

A distribuição dos cargos dos policiais afastados foi proporcional ao efetivo institucional. Agente de polícia $(67,6 \%)$, escrivão de polícia $(18,2 \%)$ e delegado $(12,9 \%)$ são os que apresentam maior número de afastamentos, mas também representam o maior efetivo da instituição policial de Santa Catarina. Estudos que avaliaram a diferença entre policiais que atuam nas áreas administrativa e operacional também concluíram não haver diferença entre elas em relação ao adoecimento profissional (Anchieta \& Galinkin, 2005; Costa et al., 2010; Minayo, Souza \& Constantino, 2007; Spode \& Merlo, 2006).

A relação entre sexo e cargo aponta que as mulheres estão em maior número nos cargos de escrivão e psicólogo - cargos mais técnicos -, ao passo que os homens ocupam a maioria dos cargos de agente de polícia e delegado. Esses dados corroboram o estudo de Minayo e Souza (2003) na Polícia Civil do Rio de Janeiro que apontou policiais mulheres principalmente em cargos técnicos e, em maior número, os homens nas atividades fins da Polícia.

A relação entre tempo de serviço e frequência de afastamento por TMC apresentou variação significativa aos 5, 15 e 25 anos de serviço, com maior concentração entre 15 e 25 anos de trabalho na instituição. Esses resultados indicam que o tempo de serviço incide na saúde do policial quando este está ainda na metade do seu tempo de serviço.

Desde setembro de 2006, está em vigor em Santa Catarina, a Lei Complementar $\mathrm{n}^{\circ}$ 335, de 2 de março de 2006 (Estado de Santa Catarina, 2006), que dispõe sobre tempo de aposentadoria para o policial civil. Desde então o policial pode se aposentar voluntariamente com proventos integrais 
quando completa 30 anos de contribuição (homens), contando com pelo menos 20 anos de exercício em atividade policial e 25 anos para as mulheres, com pelo menos 15 de exercício em atividade policial. Considerando que o teste qui-quadrado indicou que a distribuição dos quadros diagnósticos da amostra não se dá de forma aleatória, (qui-quadrado $=355,18(4)$ sig $<0,000$ ), os resultados em relação a esse aspecto impõem uma preocupação com a saúde do policial.

No caso dos afastamentos no meio do exercício da carreira (entre 14 e 17 anos), os diagnósticos mais frequentes foram os transtornos do humor (F30-39) e neuróticos, relacionados com estresse e somatoformes (F40-48). Os policiais com mais tempo de serviço apresentaram diagnósticos mais graves como esquizofrenia, transtornos esquizotípicos e transtornos delirantes (F20-29). Na pesquisa de Ferreira et al. (2008), a prevalência de problemas de saúde foi maior entre os policiais com 18 anos de serviço ou mais. Esses dados demonstram a urgência de estudos e intervenções sobre o problema, uma vez que o presente estudo não se propôs esse objetivo.

O tempo de serviço dos policiais entrevistados $(\mathrm{n}=19)$ variou de dois anos a 32 anos. O policial com dois anos de serviço relatou sofrer perseguição da chefia. Segundo referiu, antes de entrar para a Polícia já havia trabalhado em segurança privada, e nada havia mudado na sua vida pessoal nos últimos dois anos (mortes, divórcio, nascimento de filho, mudança de moradia) que justificasse seu afastamento por TMC após inserção na instituição em função de problemas pessoais. Portanto, parece que, nesse caso, as condições e a organização do trabalho aparecem como fator importante para o seu afastamento, mesmo com tão pouco tempo de atuação. Embora não tenha sido objetivo do estudo o diagnóstico de assédio moral, é muito provável que este seja o caso. $\mathrm{O}$ assédio moral é uma conduta abusiva que agride a dignidade e a integridade psíquica ou física e, em longo prazo, contribui para a doença mental (Campos, 2011).
Entre os entrevistados, o policial com maior tempo de serviço (32 anos) relata tratamento de alcoolismo durante sua vida funcional. O estudo de Minayo, Assis e Oliveira (2011) indica que, com o tempo de trabalho, o policial acumula os efeitos do estresse laboral e apresenta quadros de inadequação de comportamento, alcoolismo, agressividade, maior exposição a acidentes, ansiedade, insônia, explosões emocionais e dores crônicas. Pode-se, assim, pensar que a exposição ao trabalho incide negativamente na saúde mental dos policiais. Outros estudos apresentam resultados sobre a exposição à cultura e à organização do trabalho policial (Chaves, Costa \& Alves, 2007; Ferreira et al., 2008; Moraes, Pereira, Lopes, Rocha \& Ferreira, 2010b; Souza, Franco, Meireles, Ferreir, \& Santos, 2007; Souza \& Minayo, 2005; Spode \& Merlo, 2006).

Os transtornos mentais e comportamentais devido ao uso de substância psicoativa (F1019), quando correlacionados a algumas das variáveis do estudo indicaram resultados significativos, o que não foi registrado em outros transtornos do quadro F. Quando relacionado com o fator autonomia do IPSF, observouse que, quanto mais alto o escore, menor a tendência de apresentar diagnósticos dessa natureza $(r=-0,43, \mathrm{p}=0,068)$. O fator autonomia do IPSF, relativo a relações de confiança, liberdade e privacidade entre os membros parece ser um fator de proteção a esse tipo de transtorno. Ao ser correlacionado com dados da entrevista referente a categoria de análise sobre o desejo de continuidade da carreira policial nos filhos, insinua que os policiais com esse transtorno, querem que seus filhos sigam a carreira policial $(r=0,46, \mathrm{p}<0,05)$, o que não aparece quando correlacionamos com os outros diagnósticos de TMC. Pode-se conjecturar que, como os quadros diagnósticos de uso de substâncias têm como uma das características certo afastamento da realidade e o desejo de poder que a função profissional traz, essa pode ser a explicação para somente estes policiais apresentarem correlação.

Da mesma forma, quando foram correlacionados com a categoria da entrevista sobre a percepção do apoio recebido durante a sua 
vida, os resultados indicaram que quanto maior a presença do diagnóstico F10-19, maior a busca de apoio fora da família $(r=0,42, \mathrm{p}=0,074)$. Quanto à categoria que reporta para quem o policial falou sobre os seus sintomas, somente o diagnóstico F10-19 apresentou correlação $(r=-0,48$ e $p<0,05)$, o que sugere que os policiais com esse transtorno tendem a falar mais sobre os seus sintomas com as pessoas que não são da sua família. Talvez com o propósito de justificar os motivos que os levam a usar substâncias psicoativas, eles falem mais sobre seus sintomas e menos sobre o uso da substância.

Os resultados da entrevista com os policiais sobre sua percepção da profissão corroboram o que se encontra nas pesquisas sobre policiais: não é o trabalho em si que faz adoecer, mas a forma como o trabalho está organizado e as condições para sua realização. Isso se confirma quando se constata que a maioria das respostas sobre o que é ser policial hoje girou em torno de "uma decepção, falta de apoio, desvalorização". Esse resultado confirma os estudos de Coleta e Coleta (2008), Oliveira e Santos (2010), Spode e Merlo (2006), que indicam que a organização e a condição de trabalho são fatores mais estressores do que a exposição ao risco imposta pela profissão. O relato "fazer o necessário" citado por alguns policiais denuncia que não sentem mais realização com o trabalho e que sua atuação é apenas para cumprir obrigações.

Talvez a idealização da profissão contribua para esse resultado, pois a grande maioria dos policiais entrevistados escolheu a profissão baseada na ideia de que contribuiriam eles para um mundo melhor, comprometidos em fazer algo a favor da sociedade, como um ideal de vida, o que também fica demonstrado na pesquisa de Minayo et al. $(2007,2011)$. Esse aspecto é explicitado quando os policiais mais velhos comparam os novos policiais com eles quando começaram na Polícia, alegando que estão menos ingênuos e usam a instituição como um degrau para outros concursos em instituições como a Polícia Federal ou outras afins que oferecem melhores salários, numa crítica implícita aos novos policiais, mas, ao mesmo tempo, visualizando uma possibilidade de solução para as suas angústias em relação ao ideal profissional. Entretanto, os dados quantitativos deste estudo indicam que policiais jovens pertencentes ao quadro funcional da Polícia igualmente se afastam do trabalho por TMC.

Também para os familiares entrevistados $(n=13)$, a imagem da profissão policial é negativa, talvez influenciados pelos últimos acontecimentos na vida profissional do policial considerando o seu adoecimento. Entretanto, para a maioria dos policiais entrevistados $(\mathrm{n}=19)$, a família vê a sua profissão de forma positiva. Nos estudos de Anchieta e Galinkin (2005), Derenusson e Jablonski (2010) e Moraes et al. (2001b), ficou demonstrado que, mesmo com todas as frustrações, os policiais e seus familiares mantêm uma visão idealizada da sua função social. Derenusson e Jablonsk (2011) apontam surpresa com o resultado do seu estudo e alegam que os resultados podem ter sido influenciados pelo fato de ter sido a pesquisa realizada em um hospital da Polícia Militar. Além disso, a amostra desses estudos não era de policiais afastados por TMC.

A imagem negativa da profissão é explicitada diante do questionamento ao familiar sobre se desejaria ser policial e, para o próprio policial, se gostaria que seu filho continuasse a carreira policial. As respostas reiteraram a decepção em relação à profissão e à instituição à qual pertence. A imagem social da profissão pode contribuir para o processo de adoecimento do policial, como indicam estudos de Amador (2002), Anchieta e Galinkin (2005), Minayo et al. (2007), Minayo e Souza (2003). Segundo esses autores, a imagem negativa da profissão transforma o trabalho policial em sofrimento psicológico que só pode ser compensado pelo caráter missionário que lhe atribuem.

A rede social próxima (família, amigos próximos) e ampliada (grupos de trabalho, lazer, comunidade) pode ser influenciada por essa imagem negativa da profissão, resultando numa restrição nas relações sociais, 
conforme demonstrado. O mundo relacional, tanto do policial quanto do familiar, torna-se sua própria família; autores que estudam a importância do suporte familiar consideram que as relações sociais ampliadas são um fator importante para a saúde do indivíduo (Guest \& Biasini, 2001, Ornelas, 2008; Sluzki, 1997; Zuma, 2004).

Contribui para a restrição da rede social do policial o comportamento desconfiado em relação às pessoas, como indicado nos estudos de Minayo et al. (2007), Minayo e Souza (2003), Oliveira e Santos (2010). As entrevistas indicam que ambientes sociais mais ampliados geram tensão ao policial, por constituírem ambientes de menor controle sobre os acontecimentos, imprevisíveis naquele contexto. "Sou meio neurótica em relação ao meu filho. Ele quase vive em cárcere privado. Fico cuidando dele o tempo todo. Acho que a única retaliação que podem fazer comigo (marginais) é fazer algo com meu filho (ou matá-lo ou aliciá-lo para o tráfico)" (PC 7).

As dificuldades advindas de um suporte social restrito podem ser compensadas pelo suporte familiar consistente, que, segundo Baptista (2005), é um dos mais relevantes amortecedores do efeito de diversos estressores na vida das pessoas, tornando-o fundamental nos estudos de resiliência psicológica em relação aos processos de adoecimento. Os resultados indicam que, dos 19 policiais entrevistados, apenas dois responderam não contar com ninguém. Esses dados dão indícios de que, para esses policiais, não há uma figura concreta para compartilhar suas alegrias e tristezas. Sluzki (1996), no seu trabalho sobre as redes sociais, propõe níveis relacionais que vão do mais íntimo ao superficial e que expressam o quanto o indivíduo pode recorrer a essa rede social no momento em que necessitar de ajuda. Quanto maior a possibilidade de ajuda que o indivíduo possui, maior será seu recurso para resolução de problemas.

Contudo os resultados indicados pelo IPSF apontaram que o policial tem uma percepção positiva sobre a privacidade e confiança entre os membros da família, fator importante considerando o comportamento desconfiado citado anteriormente. Assim, configura-se uma rede social restrita, mas de qualidade, com a qual o policial pode contar, como indica o relato: "Não tenho amigos pra compartilhar. Meu pai e mãe são minha âncora e minha esposa é muito sensata. Eles me fazem pensar sobre minhas decisões, mas o que eu decido eles apoiam" (PC 3).

Os resultados apontam que pedir ajuda é uma atitude difícil para o policial: cinco policiais afirmam pedir auxílio explicitando verbalmente, ao passo que oito dizem não pedir qualquer tipo de ajuda. Outros seis policiais relatam dificuldade de pedir ajuda para resolução de problemas pessoais. Levando-se em conta que a comunicação não se dá somente pela expressão oral, quando respondem à pergunta "como as pessoas sabem que você está precisando de ajuda?", configura-se outro panorama sobre o reconhecimento da família a respeito do comportamento do policial quando este precisa de ajuda, embora dois policiais tenham afirmado não demonstrar qualquer necessidade. Para os familiares, de modo geral, o comportamento do policial que indica que algo não vai bem e que ele está precisando de ajuda é quando ele tem uma atitude de ficar quieto e isolar-se. Esse comportamento do policial cria uma sobrecarga para a rede familiar prestar auxílio. Segundo Amador, Santorum, Cunha e Braum (2002), não é comum para os policiais conversarem com a família sobre o que passaram durante o serviço para não preocupá-la, embora reconheçam a importância de se desligarem do trabalho para se relacionarem com a família após um dia de trabalho.

Quanto às demonstrações de afeto do policial, surge um conflito entre as respostas dos policiais e as dos familiares. Sete policiais relatam que não demonstram afeto, mas não foi isso que a família respondeu. No estudo de Derenusson e Jablonski (2010), as manifestações de afetividade dos policiais na visão do familiar obtiveram um nível geral alto, especialmente no que diz respeito ao relacionamento do policial com os filhos, mas os autores não indicaram a que manifestações se referem. Amador et al. (2002) 
apresentam um dado da sua pesquisa que pode ajudar a compreender um pouco melhor esse resultado: para controlar a subjetividade do policial, com o objetivo de manter sua imparcialidade nas ações policiais, há um propósito da instituição de endurecê-lo e criar resistências que visem ao bom exercício da profissão.

Durante a entrevista, ficou demonstrado que, tanto na visão da família quanto na visão do policial, mesmo com rede social restrita, focada na família, o policial e o familiar esperavam que a instituição se mostrasse mais próxima e disponível para ajudá-lo no momento de afastamento do trabalho. Alguns citaram como apoio os amigos do trabalho, o delegado, o psicólogo da instituição, mas não consideradas como ações da instituição. Ferreira et al. (2008), Minayo e Souza (2003) e Spode e Merlo (2006) alertam para a importância do suporte social, tanto dos superiores quanto dos colegas na instituição policial, visto que vínculos de confiança e cooperação são fundamentais em função da natureza do trabalho permeado de riscos.

O suporte social revelado nas entrevistas mostra que tanto o familiar quanto o policial têm visões comuns sobre para quem falaram e com quem contaram quando problemas de saúde estiveram presentes e o levaram ao afastamento do trabalho. Nessa categoria, o médico e o psicólogo foram citados na resposta do policial e do familiar como focos de ajuda na percepção de ambos. Esse dado indica que a rede de saúde do trabalhador é importante para a percepção de apoio durante o processo de afastamento do trabalho e corrobora estudos já citados.

A percepção dos sinais e sintomas de que algo não estava bem com o policial antes do seu afastamento se expressou mais fortemente na atitude de irritabilidade e agressividade, na perspectiva do policial, e na atitude de isolamento, na visão da família. Aspecto importante demonstrado nos resultados é que, para os policiais, os sinais revelados são de ordem mais introspectiva do que para os familiares, sintomas que se não forem explicitados pelo indivíduo que sente, não poderão ser nominados por quem está ao lado. Na pesquisa, são revelados pelo policial e nem citados pelos familiares. Os sinais percebidos pelos familiares dizem respeito àquilo que o policial permite revelar ou que $o$ familiar consegue observar. Esse dado sugere que o policial nem sempre conta o que está sentindo para a pessoa da família mais próxima a ele. Apenas seu comportamento demonstra que algo não vai bem com ele. Tais sintomas confirmam a categoria pesquisada sobre a sua atitude de pedir ajuda e também os resultados encontrados nos estudos de Costa et al. (2007), Dantas et al. (2010), e Rosseti et al. (2008).

O risco de não pedir ajuda ou de não revelar o que está sentindo é de o sofrimento psicológico ser percebido apenas quando a sua intensidade está extrema, como no caso da tentativa de suicídio revelado por um familiar e nas tentativas e ideias suicidas apresentadas por três policiais. O estudo de Oliveira e Santos (2010) demonstrou que 20,8\% da sua amostra já pensaram em se suicidar em algum momento da vida profissional. Amador (2002), Minayo et al. (2007) e Minayo e Souza (2003) mencionam que o suicídio em policiais revela o elevado risco decorrente do trabalho, que envolve fatores como as condições de trabalho, o exercício de atividades extras que não permitem o descanso e o não reconhecimento social da profissão, situação em que o apoio social e familiar torna-se fundamental. A literatura sugere uma associação inversa entre o nível de apoio social e a ocorrência de sofrimento psíquico (Frydman, 1981; Holahan \& Moos, 1981). Chor, Griep, Lopes e Faerstein (2001) também apontam para o benefício proporcionado pela participação e pela integração social na percepção de bem-estar relacionado com o aumento da satisfação de vida, a autoestima e a diminuição de sintomatologia.

Não obstante, segundo referência de um policial entrevistado, na Polícia, aprendem a não falar sobre os problemas do trabalho porque estão permeados de informações que fazem parte de processos de investigação ou outras questões que exigem sigilo. Esse dado foi também encontrado no estudo de 
Derenusson e Jablonski (2010). Isso pode explicar os resultados relativos aos motivos que levaram o policial ao afastamento do trabalho na perspectiva dos familiares quando aparecem duas indicações de problemas pessoais como motivadores do afastamento, citados somente pelos familiares, visto que os policiais não podem falar sobre o trabaIho. Entretanto, tanto os policiais quanto os familiares indicaram como responsáveis pelo adoecimento os problemas relacionados ao trabalho e também a junção de problemas no trabalho e familiares, aspecto destacado pelos policiais e por dois familiares. Oliveira e Santos (2010) demonstraram que tanto os problemas do trabalho afetam o relacionamento familiar do policial quanto os problemas familiares afetam o desempenho no trabalho, especialmente quando aliados à exposição ao risco, estresse e baixa remuneração.

Dentre os motivos de afastamento do trabalho relacionados pelos familiares e policiais, as situações de conflito com as chefias e colegas de trabalho foram as mais citadas. Embora não sendo o objetivo do presente estudo, alguns motivadores de afastamento citados por policiais e familiares tinham características de assédio moral, conforme se fez referência anteriormente, havendo inclusive um encaminhamento direto de um dos casos à assistente social da Perícia Médica para avaliar e, se necessário, intervir. Outra situação foi o afastamento de um policial por Transtorno de Estresse Pós-traumático (TEPT) por presenciar situação de violência no trabalho. A literatura pesquisada também apresenta dados sobre a vitimização do policial (Minayo et al., 2007, Oliveira \& Santos, 2010), corroborando os resultados encontrados.

Por fim, o impacto que a profissão provoca nas relações familiares pode ser observado quando o policial e o familiar se referem à mudança de comportamento percebido por ambos, depois de sua inserção na Polícia, situação também apontada nos estudos de Minayo e Souza (2003) e Derenusson e Jablonski (2010). De fato, na amostra estudada, o comportamento de desconfiança do policial foi o mais citado por ele próprio. Para o familiar, foi o comportamento estressado que recebeu a maior carga de ocorrência. Para essa população, o termo estressado se referia a: estar atento, em sinal de alerta, como se algo ruim pudesse acontecer a qualquer momento, irritado, agressivo, explosivo. Em relação à característica de desconfiança presente no policial, há concordância entre o familiar e o policial, ocasionando, segundo os familiares, afastamento relacional entre ambos, aspecto também explicitado no estudo de Coleta e Coleta (2008).

Acredita-se que a valorização do suporte familiar e social possa estimular as relações interpessoais para que o trabalho não seja somente fonte de sofrimento, minimizando os efeitos danosos à saúde do policial. Intervenções e programas de apoio institucional ao policial afastado do trabalho podem contribuir e muito para um retorno mais saudável ao trabalho. Contudo, os resultados deste estudo reiteram que as condições e a organização do trabalho da instituição policial contribuem para o adoecimento do policial. É nesse quesito que se pode esperar uma mudança mais profunda na instituição a favor do trabalhador e, consequentemente, a favor da população que usa o serviço da Polícia.

\section{Conclusão}

A percepção do suporte familiar por parte dos policiais indicou ser este um recurso importante para o curso de seu afastamento do trabalho por TMC e de sua recuperação. Esses resultados corroboram a existência de uma associação inversa entre o nível de apoio social e a ocorrência de sofrimento psíquico indicada em literatura já citada. Conclui-se que o incentivo à valorização do suporte familiar e social e o estímulo às relações interpessoais, na família, no trabalho e nas relações sociais ampliadas, tornam-se ferramentas importantes para a percepção de bem-estar e se relacionam com o aumento da satisfação de vida, da autoestima e, por consequência,, contribuem para o controle dos sintomas.

Os resultados não apresentaram conteúdos sobre as condições e a organização de trabalho do policial, pois não era esse o foco 
do estudo. É preciso registrar, porém, que os policiais - e seus familiares - demonstraram bastante insatisfação em relação às condições e à organização do trabalho, considerando-os como responsáveis pelo adoecimento, muito mais do que os riscos da profissão em si. Isso indica que a Polícia precisa agir preventivamente, ou seja, criar programas que contribuam para a saúde do policial, com a reflexão de como as condições e a organização do trabalho da instituição contribuem para o adoecimento.

Embora o presente estudo tenha tido pouca adesão por parte dos policiais para a realização das entrevistas, considerando a experiência da autora no atendimento psicológico a policiais e familiares de 1997 a 2010, pode-se concluir que os resultados confirmam a realidade encontrada na Polícia Civil de Santa Catarina. Os dados demonstrados legitimam a importância da presença da instituição no cuidado com a saúde do policial, não só em sua promoção e prevenção, mas também durante o período de LTS, quando o policial se encontra afastado do trabalho para a realização de tratamento do quadro diagnóstico apresentado.

O fato deste estudo não comparar perfis de policiais afastados por TMC entre estados brasileiros restringe a possibilidade de generalização dos seus resultados, uma vez que cada região apresenta diferenças relativas às condições de trabalho e à estrutura de gestão do trabalho policial. De outro modo, o número restrito de policiais entrevistados ( $\mathrm{n}=19)$, devido a questões éticas já citadas anteriormente, inibe reflexões sobre a articulação entre quadros diagnósticos e suporte familiar, objetivo do estudo. Tornase necessário a realização de outros estudos sobre o tema que permitam maior acesso aos policiais que se encontram na condição de afastamento do trabalho por TMC.

Programas voltados à saúde do policial são fundamentais para uma Polícia sólida e competente, e o policial é somente uma parte do processo. As pesquisas indicam que a Polícia precisa reavaliar sua organização de trabalho e as condições a que estão expostos os policiais. Enquanto isso não acontecer, o policial vai continuar sendo responsável por não saber administrar adequadamente as situações resultantes do trabalho a que está exposto, por não ter resiliência suficiente para lidar com aspectos inerentes à profissão e adoecer, ao passo que a Polícia vai continuar com as dificuldades de ter um efetivo capaz de suportar os meandros da profissão com a competência esperada. 


\section{Maria Cristina d'Avila de Castro}

Mestre em Psicologia pela Universidade Federa de Santa Catarina, Florianópolis - SC. Brasil.

E-mail: mcrisdavilafloripa@gmail.com

\section{Roberto Moraes Cruz}

Doutora em Engenharia de produção pela Universidade Federal de Santa Catarina, Florianópolis - SC. Brasil. Docente da Universidade Federal de Santa Catarina, Florianópolis - SC. Brasil.

E-mail: robertocruzdr@gmail.com

Endereço para envio de correspondência:

Av Rio Branco, 448/702, Centro. CEP: 88080-000. Florianopolis - SC. Brasil.

Recebido 25/03/2013, $1^{\text {a }}$ Reformulação: 28/08/2013, Aprovado 29/08/2013. 
Referências
Amador, F. S. (2002). Violência policial: Verso e reverso do sofrimento. Santa Cruz do Sul, RS: EDUNISC.

Amador, F. S., Santorum, K., Cunha, C. S., \& Braum, S. M. (2002). Por um programa preventivo em saúde mental do trabalhador na brigada militar. Psicologia: Ciência e Profissão, 22(3), 54-61.

Anchieta, V.C.C., \& Galinkin, A. L. (2005). Policiais civis: Representando a violência. Psicologia \& Sociedade, 17(1), 17-28.

Andrade, E.R., Souza, E. R., \& Minayo, M. C. S. (2009). Intervenção visando a auto-estima e qualidade de vida dos policiais civis do Rio de Janeiro. Ciência \& Saúde Coletiva, 14(1), 275-285.

Antunes, C. \& Fontaine, A. M. (2005). Percepção de apoio social na adolescência: análise fatorial confirmatória da escala social Support Appraisals. Paidéia, 15, 355-366.

Baierle, T., \& Merlo, A. (2008). Saúde mental e subjetividade no trabalho de uma guarda municipal: Estudo em psicodinâmica do trabalho. Cadernos de Psicologia Social do Trabalho, 11(1), 69-81.

Baptista, M. (2005). Desenvolvimento do inventário de percepção de suporte familiar (IPSF): estudos psicométricos preliminares. Psico-USF, 10(1), 11-19.

Baptista, M. (2009). Inventário de Percepção de Suporte Familiar (IPSF). São Paulo, SP: Vetor.

Campos, E. P. (2004). Suporte social e família. In: J Mello Filho (Org.), Doença e família (pp. 141-61). São Paulo, SP: Casa do Psicólogo,

Campos, I. M. C. (2011) Evidências de assédio moral e incapacidade para o trabalho em servidores públicos de Santa Catarina. Tese de Doutorado. Programa de Pós-Graduação em Engenharia de Produção da Universidade Federal de Santa Catarina, Florianópolis, SC.

Campos, I. C. M., \& Cruz, R. M. (2007). Diagnóstico de transtornos mentais e comportamentais e relação com o trabalho de servidores públicos estaduais. In: Secretaria do Estado da Administração. In I Coletânea de Trabalhos Científicos Produzidos pelos Servidores Públicos (pp. 15-42). Florianópolis, SC: Diretoria de Gestão Documental.
Cantelli, E. F., Motta, F., \& Castro, M. C. A. (2010). Gerenciamento do estresse em servidores da Segurança Pública: Pesquisa sobre intervenções institucionais em Santa Catarina. Segurança \& Sociedade, 1, 153-170.

Carvalho, I. M. M., \& Almeida, P. H. (2003). Família e proteção social. São Paulo em Perspectiva, 17(2), 109-122.

Carvalho, S. C. A., Carvalho, A. L. A., Lucena, S. C., Coelho, J. P. S., \& Araújo, T. P. B. (2008). Associação entre bruxismo e estresse em policiais militares. Revista Odonto Ciência, 23(2): 125-129.

Chaves, P. G. S, Costa, P. L., \& Alves, T. M. O. (2007). Saúde mental e o trabalho policial: Resultado do levantamento de dados na Delegacia Especializada. Recuperado em 10 de outubro de 2011 de:http://www. observatorionacionaldoidoso.fiocruz.br/ biblioteca/_artigos/4pdf

Chor, D., Griep, R., Lopes, C., \& Faerstein, E. (2001). Medidas de rede e apoio social no estudo pró-saúde: Pré-testes e estudo piloto. Cadernos de Saúde Pública, 17(4), 887-896.

Coleta, A., \& Coleta, M. (2008). Fatores de estresse ocupacional e coping entre policiais civis. Psico-USF, 13(1), 59-68

Costa, A., \& Ludermir, A. B. (2005). Transtornos mentais comuns e apoio social: estudo em comunidade rural da zona da mata em Pernambuco, Brasil. Cadernos de Saúde Pública, 21(1), 73-79.

Costa, M., Accioly Júnior, O., \& Maia, E. (2007). Estresse: Diagnóstico dos policiais militar em um cidade Brasiléia. Revista Panamericana de Salud Publica, 21(4):217-22.

Costa, S. H. N., Cunha, L. C., Yonamine, M., Pucci, L. L., Oliveira, F. G. F., Souza, C. G. et al. (2010). Survey on the use of psychotropic drugs by twelve military Police units in the municipalities of Goiânia and Aparecida de Goiânia, state of Goiás, Brazil. Revista Brasileira de Psiquiatria, 32(4), 389-395.

Cruz, R. M. (2010). Nexo técnico e vigilância à saúde do trabalhador: uma agenda científica para o NTEP. In: Machado, J., Soratto, L., \& Codo, W. (Org, ), Saúde e trabalho no Brasil: uma revolução silenciosa (256-272). Petrópolis, R.J.: Vozes. 
Cunha, E. F. C., Carvalho, M. M. S. B., Santos, C.A., Ferreira, E. L., Barros, M. M. S. \& Mendonça, A. C. M. (2009). Aspectos sócioemocionais de mães de bebês prematuros. Psicologia \&m Foco, 2(1), 35-44.

Dancey, C.P., \& Reidy, J. (2008). Estatística sem matemática para Psicologia: Usando SPSS para Windows (3a ed). Porto Alegre, RS: Artmed.

Dantas, M. A., Brito, D. V. C., Rodrigues, P. B., \& Maciente, T. S. (2010). Avaliação de estresse em policiais militares. Psicologia: Teoria e Prática, 12(3), 66-77.

Derenusson, F. C., \& Jablonski, B. (2010). Sob fogo cruzado: o impacto do trabalho policial militar sobre a família policial. Aletheia, 32, 22-37.

Estado de Santa Catarina. (2006). Lei Complementar $n^{\circ} 335$, de 2 de março de 2006. Dispõe sobre a aposentadoria especial dos integrantes do Grupo Segurança Pública - Polícia Civil, Grupo Segurança Pública Sistema Prisional e Grupo Segurança Pública - Sistema de Atendimento ao Adolescente Infrator, nos termos do disposto no art. 40, $\S 4^{\circ}$, II e III, da Constituição da República e estabelece outras providências. Diário Oficial do Estado, (17835), de 2 de março de 2006.

Ferreira, D. K., Augusto, L., \& Silva, J. (2008). Condições de trabalho e percepção da saúde de policiais militares. Cadernos de Saúde Coletiva, 16(3), 403-420.

Fortes, S., Villano, L. A. B., \& Lopes, C. S. (2008). Nosological profile and prevalence of common mental disorders of patients seen at the Family Health Program (FHP) units in Petrópolis, Rio de Janeiro. Revista Brasileira de Psiquiatria, 30(1), 32-37.

Frydman, M. I. (1981). Social support, life events and psychiatric symptoms. A study of direct conditional and interactions effects. Social Psychiatry, 16, 69-78.

Glina, D. M. R., Rocha, L. E., Batista, M. L., \& Mendonça, M. G. V. (2001). Saúde mental e trabalho: Uma reflexão sobre o nexo com o trabalho e o diagnóstico, com base na prática. Cadernos de Saúde Pública, 17(3), 607-616.

Gonçalves, T. R., Pawlowski, J., Bandeira D. R. \& Piccinini, C. A. (2011). Avaliação de apoio social em estudos brasileiros: aspectos conceituais e instrumentos. Ciência \& Saúde Coletiva, 16(3), 1755-1769.

Guest, K. C., \& Biasini, F. J. (2001). Middle childhood, poverty, and adjustament: Does social support have an impact? Psychology in the School, 38(6), 549-560.

Holahan, C.J., \& Moos, R.H. (1981). Social support and psychological distress: A longitudinal analysis. Journal of Normal Psychology, 90(4), 165-170.

lacoponi, E. (1997). Detecção de distúrbios emocionais pelo médico: impacto do tipo de trabalho médico e do conceito sobre doenças mentais. Revista de Ciências Médicas, 6, 41-5.

Jaques, M. G. C. (2007). O nexo causal em saúde/ doença mental no trabalho: Uma demanda para a psicologia. Psicologia \& Sociedade, 19(esp), 112-119.

Ludermir, A.B., \& Melo Filho, D. A. (2002). Condições de vida e estrutura ocupacional associadas a transtornos mentais comuns. Revista de Saúde Pública, 36(2), 213-221.

Maragno, L., Goldbaum, M., Gianini, R. J., Novaes, H. M. D., \& César, C. L. G. (2006). Prevalência de transtornos mentais comuns em populações atendidas pelo Programa Saúde da Família (QUALIS) no Município de São Paulo, Brasil. Cadernos de Saúde Pública, 22(8), 1639-1648.

Matsukura, T. S., Marturano, E. M., \& Oishi, J. (2002). O questionário de suporte social (SSQ): estudos de adaptação para o português. Revista Latino-Americana de Enfermagem, 10(5), 685-691.

Medronho, R. A., Bloch, K. V., Luiz, R.R., \& Werneck, G. L. (2009). Epidemiologia (2a ed.). São Paulo, SP: Atheneu.

Minayo, M. C. S.; Souza, E. R., \& Constantino., P. (2007) Riscos percebidos e vitimização de policiais civis e militares na (in) segurança pública. Cadernos de Saúde Pública, 23(11), 2767-2779.

Minayo, M. C. S, Assis, S. G. \& Oliveira, R. V. C. (2011). Impacto das atividades profissionais na saúde física e mental dos policiais civis e militares do Rio de Janeiro (RJ, Brasil). Ciência \& Saúde Coletiva, 16(4), 2199-2209. 
Minayo M. C. S., \& Souza, E. R. (Orgs.). (2003). Missão Investigar: Entre o ideal e a realidade de ser policial. Rio de Janeiro, RJ: Garamound.

Moraes, L. F. R., Pereira, L. Z., Lopes, H. E. G., Rocha, D. B., \& Ferreira, S. A. A. (2001b). Estresse e qualidade de vida no trabalho na Polícia Militar do Estado de Minas Gerais. Anais do $24^{\circ}$ Encontro Anual da Associação Nacional dos Programas de Pós Graduação (ENANPAD.- GRT.535). Recuperado em 5 de setembro de 2011 de http://www.anpad.org. br/admin/pdf/enanpad2001-grt-359.pdf

Moraes, L. F. R., Pereira, L. Z. \& Souza, K. O. (2001a). Implicações do gênero na qualidade de vida e estresse no trabalho da Polícia Militar do Estado de Minas Gerais. In Anais do Conifes - OGT 1401. Recuperado em 5 de setembro de 2011 de http://www. ichs.ufop.br/conifes/anais/OGT/ogt1401

Oliveira, P. L. M, \& Bardagi, M. P. (2010). Estresse e comprometimento com a carreira em policiais militares. Boletim de Psicologia, 59(131), 153-166.

Oliveira, K. L. \& Santos, L. M. (2010). Percepção da saúde mental em policiais militares da força tática e de rua. Sociologias, 12(25), 224-250.

Ornelas, J. (Org.). (2008). Psicologia comunitária. Lisboa: Sociedade Unipessoal.

Rosseti, M. O., Ehlers, D. M., Guntert, I. B., Leme, I. F. A. S., Rabelo, I. S., Tosi, S. M. V. D., et al. (2008). O inventário de sintomas de stress para adultos de Lipp (ISSL) em servidores da Polícia Federal de São Paulo. Revista Brasileira de Terapias Cognitivas, 8(2), 108-119.

Savoia, M. G. (1999). Escalas de eventos vitais e de estratégias de enfrentamento (coping). Revista de Psiquiatria Clínica, 26(2), 57-67.

Seidl, E. M. F., Troccóli, B. T., \& Zannon, C. M. L. C. (2001). Análise fatorial de uma medida de estratégias de enfrentamento. Psicologia: Teoria e pesquisa, 17(3), 225-234.

Silva, E. P., Fabbro, M. R. \& Heloani, R. (2009). $\mathrm{O}$ trabalho de enfermeiras e guardas municipais: identidade, gênero e poder. Interface, 13(31), 395-407.

Sluzki, C. (1997). A rede social na prática sistêmica. São Paulo, SP: Casa do Psicólogo.

Souza, E. R., \& Minayo, M. C. S. (2005). Policial, risco como profissão: morbimortalidade vinculada ao trabalho. Ciência e Saúde Coletiva, 10(4), 917-928.

Souza, E. R., Franco, L. G., Meireles, C. C., Ferreira, V. T., \& Santos, N. C. (2007). Sofrimento psíquico entre policiais civis: uma análise sob a ótica de gênero. Cadernos de Saúde Pública, 23(1), 105-114.

Souza, M. S. \& Baptista, M. N. (2008). Associações entre suporte familiar e saúde mental. Psicologia Argumento, 26(54), 207-215.

Souza, M., Baptista, M., \& Alves, G. E. (2008). Suporte familiar e saúde mental: evidência de validade baseada na relação entre variáveis. Aletheia, 28, 45-59.

Souza, M. S., Baptista, A. S. D \& Baptista, M. N. (2010). Relação entre suporte familiar, saúde mental e comportamentos de risco em estudantes universitários. Acta Colombiana de Psicología, 13(1), 143-154.

Spode, C. B. \& Merlo, A. R. C. (2006). Trabalho policial e saúde mental: Uma pesquisa junto aos capitães da polícia militar. Psicologia: Reflexão e Crítica, 19(3), 362-370.

Zuma, C. E. (2004). A visão sistêmica e a metáfora de rede social no trabalho de prevenção de violência intrafamiliar em comunidades. Nova Perspectiva Sistêmica. 13(23). 